RESEARCH AND PRACTICE

\title{
Adapting a physical activity intervention for youth in a rural area: A case study
}

\author{
Moya L. Alfonso, PhD, MSPH${ }^{1}$, Gavin Golquitt, EdD², Ashley Walker, PhD, CHES ${ }^{1}$, Akrati Gupta, DrPH Candidate, MPH $^{1}$ \\ ${ }^{1}$ Department of Community Health Behavior and Education, Jiann-Ping Hsu College of Public Health, Georgia Southern University, Statesboro, \\ GA; ${ }^{2}$ School of Health and Kinesiology, College of Health and Human Sciences, Georgia Southern University, Statesboro, GA
}

\begin{abstract}
Background: Physical activity offers children and youth many well-documented positive effects on health. The present study adapted a community-based prevention marketing campaign (CBPM), VERB ${ }^{\mathrm{TM}}$ Summer Scorecard (VSS) to promote physical activity among minority youth in rural, southeast Georgia. The purpose of this paper is to describe the adaptation process, emphasizing methods used and lessons learned.
\end{abstract}

Methods: A qualitative study design was used to identify social marketing concepts that informed program adaptation, including two focus groups with 12 children and two focus groups with 14 parents. Qualitative thematic data analysis was used to analyze formative research. The adapted program was implemented for three summers, from 2012 through 2014 . A case study of program implementation and lessons learned is provided.

Results: Formative research results suggested two changes to VSS that would be required for the program to work in this rural community - a focus on parent-child activities instead of a sole focus on youth and changes to the Scorecard that was used to track physical activity. Over the course of three years of implementation, several lessons were learned about university-community partnerships (e.g., the need for a balance of power), having a program champion, and program evaluation.

Conclusions: Rural communities are a unique context, with barriers to health promotion efforts that serve to contribute to negative health behaviors and resistance to change. The limited capacity of rural communities to address physical activity makes these barriers difficult to overcome, even during implementation of evidence-based practices.

Key Words: Youth, obesity, evidence-based interventions, rural

\section{INTRODUCTION}

Physical activity offers children and youth many welldocumented positive effects on health. Youth engaging in physical activity have better cardiorespiratory health, muscle fitness, and bone health (Centers for Disease Control and Prevention (CDC), 2015a). Moreover, being physically active helps control body weight, reduce anxiety and stress, and increase self-esteem (CDC, 2015a). Also, since active youth are more likely to turn into active adults, they lower their risk of acquiring many chronic diseases including heart diseases and cancer (CDC, 2015a).

Disparities Related to Physical Activity and Obesity in the United States and Georgia

The 2013 Youth Risk Behavior Surveillance Survey (YRBSS) indicated that $13.7 \%$ of adolescents are obese and another $16.6 \%$ are overweight (CDC, 2015b). Moreover, the percentage of children 6 to 11 years of age who were obese increased from 7\% in 1980 to 18\% in 2012 (CDC, 2015b). Healthy lifestyle habits such as physical activity can lower the risk of childhood obesity. The US Department of Health and Human Services (DHHS) recommends that youth aged 6 to 17 years of age should participate in at least 60 minutes of daily physical activity. However, according to YRBSS 2013, only $27.1 \%$ of adolescents meet daily physical activity recommendations (CDC, 2015b).
The state of Georgia has lower rates of physical activity among adolescents compared to national averages (CDC, 2015b). The 2013 YRBSS data for Georgia indicate that only $24.7 \%$ of adolescents meet the Department of Health and Human Service's (DHHS) recommendations for daily physical activity, and $18.7 \%$ performed no physical activity (CDC, 2015b). Although Georgia has lower rates of obesity $(12.7 \%)$, it has more than twice the percentage of overweight adolescents (34.5\%) compared to national percentages (CDC, 2015b).

Childhood obesity is a health concern for children in most communities, but those living in certain areas are more susceptible. Minority children (African-American or Hispanic) living in rural areas are $25 \%$ more likely to be overweight or obese than those living in metropolitan areas (Corbett et al., 2014). The characteristics of rural communities contribute to the problem of childhood obesity; rural communities face barriers such as higher poverty levels, less access to places for physical activity, and limited resources to provide healthy food and physical education at schools (Corbett et al., 2014).

Disparities in health outcomes and physical activity among race/ethnic groups are more pronounced in southern states, such as Georgia (Corbett et al., 2014; Martin et al., 2005). Since regular physical activity can be beneficial in 
preventing and managing various physical and emotional health conditions, measures should be taken to improve the levels of physical activity among children in Georgia as a step towards combating chronic health conditions (Brown \& Summerbell, 2008; Corbett et al., 2014; Janssen \& LeBlanc, 2010; Nemet et al., 2005; Warburton, Nicol \& Bredin, 2006).

The need to address health disparities among adolescents is also a focus of Healthy People 2020 (HP2020) (DHHS, 2010). The two issues cited in HP2020 center around the increasing proportion of minority youth in this population and the need for innovative interventions that focus on prevention (DHHS, 2010). The present study adapted a community-based prevention marketing campaign (CBPM), VERB $^{\mathrm{TM}}$ Summer Scorecard (VSS; Alfonso et al., 2013; Alfonso et al., 2011; Bryant et al., 2010) to promote physical activity among minority youth in rural, southeast Georgia.

\section{Development of the VERB Summer Scorecard}

In 2003, the Florida Prevention Research Center provided technical assistance and support to a coalition of over 50 organizations in Kentucky to use CBPM (Bryant et al., 2010) in designing strategies to prevent childhood obesity. For its first project, a Community Advisory Board (CAB) selected youth ages 8 - 13 years of age (i.e., 'tweens' - a marketing term commonly used in public health) as its primary target audience and physical activity as the behavioral focus for its first project. With the CBPM framework, the CAB conducted formative research and used results to design a community-based extension of the national campaign, $V E R B^{T M}$ - It's what you do (Alfonso et al., 2011). A key element of the resulting VSS program was the creation of action outlets (i.e., free and low-cost places for youth to be active). During summers, the Scorecard became a "ticket" for entry to a variety of fun physical activities, such as free swimming at public pools, Muscle Mania classes, 2-for-1 skating, and other action-oriented games and events (Alfonso et al., 2011). Tweens used the Scorecard to track their physical activity. When they had been active for a designated period of time (typically an hour) at a scorecard site or at home, an adult signed 1 of the 24 squares on the card (Alfonso et al., 2011). When all squares were filled, the card was redeemable for physical activity-themed prizes, such as Frisbees, beach towels, and water bottles, and made youth eligible for a grand prize drawing of larger prizes - bikes, taekwondo lessons, YMCA memberships, and running shoes (Alfonso et al., 2011).

VSS increases parents' and community partners' commitment to provide physical activity opportunities for youth. The scorecard and accompanying materials make it easier for parents to keep their children active and help action outlets attract tweens to new types of physical activity (Alfonso et al., 2011). The success of this program in Kentucky and in Florida supports the theory that multilevel interventions are effective in achieving behavior change and eliminating health disparities (Alfonso et al., 2013; Alfonso et al., 2011; Trickett \& Beehler, 2013). The present effort attempted to replicate the success of this program in a rural Georgia community, along with the qualitative formative research that was conducted to gather a better understanding of the target community and audience. The purpose of this report is to describe the process of program adaptation, with an emphasis on methods used and lessons learned. Because rural areas may have lower capacity to address physical activity, qualitative formative research was conducted and changes were made to the underlying VSS social marketing framework (Alfonso et al., 2008).

\section{METHODS}

Qualitative formative research, a basic element of the social marketing approach, was used to gather information on characteristics of the target audience that might affect uptake of physical activity in a minority, rural population. A qualitative design was used because of the need to gather information from youth and families; statistical data were not gathered. A CAB, including school personnel, community leaders, and other concerned organizational representatives, was created. Focus groups with African American parents and their children were conducted in partnership with the local Boys and Girls Club, our lead community partner. Two focus group discussions were conducted with youth ( $\mathrm{N}=12$ across groups; 6 males and 6 females), and two focus groups were conducted with parents ( $\mathrm{N}=14$ across groups; 6 males and 8 females). Focus group participants were low-income and African American. As is typical of qualitative, exploratory research, there was no hypothesis. Parents and youth were asked about their current physical activity and about barriers and benefits associated with physical activity. They were read a description of the VSS program and asked their general opinions of it and how and whether the program would work in their community. Emphasis was placed on what would need to be revised about VSS in order for it to work in rural Georgia. Recruitment strategies included passing out flyers at the Boys and Girls Club and offering a \$20 cash incentive to parents and a \$10 cash incentive to youth. Focus groups with parents and youth lasted approximately one hour and were held at the Boys and Girls Club, a location convenient to both groups. Focus group discussions were audiorecorded, and transcripts were created. A codebook was developed based upon the focus group guide and applied to the transcripts. Coders discussed transcripts and came to consensus on coding. Once themes were identified, a social marketing plan was created and shared with the CAB for decision-making purposes. In addition, field notes taken during coalition meeting were consulted for documentation of strategic-decision making, implementation, and lessons learned. The Institutional Review Board approved the formative research protocol.

\section{RESULTS}

Conducting qualitative formative research prior to implementing an evidence-based intervention such as VSS is essential when transferring the innovation to a new community. The following sections present the research results, organized in a framework of social marketing planning: 


\section{Desired Outcomes}

Formative research identified the following desired outcomes for tweens and their families: increased selfefficacy for being physically active, increased odds of having tried a new physical activity, increased moderate to vigorous physical activity, increased physical fitness as measured by Fitness Gram (Plowman \& Meredith, 2013), increased odds of obtaining the President's Physical Fitness award, increased sense of connection to their community (i.e., engaging in community-based, prosocial activities), and increased sense of connection to their families. As originally developed, VSS was not for families (Alfonso et al., 2013; Alfonso et al., 2011; Bryant et al., 2010); the sole focus was on youth trying new activities and being more physically active. Thus, the program, needed to be more family oriented. As decided in the focus groups, desired outcomes for families included: increased self-efficacy for fitting physical activity into the family schedule, increased family-child participation in moderate to physical activity, and an increased sense of community.

\section{Context for the Goals}

VSS was implemented in Bulloch County, GA, a rural community in Southeast Georgia. This county provides limited opportunities for free or reduce-price physical activities. Locations included the Clubhouse (bowling, golf, laser tag) and Splash in the Boro (a water park). Many youth are involved with the Boys and Girls Club of Bulloch and with the Parks and Recreation Department. Based on an assessment of the program context during the research phase, we decided to recruit participants via the Boys and Girls Club of Bulloch and the Parks and Recreation Department. Cool Deals (i.e., opportunities for free and low cost activities for targeted youth and families) were offered via the Clubhouse (i.e., free bowling with a Scorecard) and Splash in the Boro (i.e., a free ticket with the purchase of one ticket with a Scorecard).

\section{Target Audiences}

The results showed that the primary audience for VSS was 8 - 13 year olds, most of whom were underserved and minority youth, who attended either the Boys and Girls Club or the Parks and Recreation Department. Secondary audiences included immediate families and extended families of 8 - 13 year olds who attended the Boys and Girls Club or the Parks and Recreation Department, most of whom were underserved and minority families. According to the results of the focus groups, families were particularly relevant. Both parents and children expressed a desire for parents and other family members to participate directly in the physical activities.

Since VSS is a community-based program, other sources of support were essential to the success of the project. Formative research identified other sources of support. The central community partner was the Boys and Girls Club of Bulloch. Official sponsors included the C.H.I.L.D. coalition and the Rural Health Institute. Additional sources of support included local elementary and middle schools, restaurants, physical activity outlets (i.e., the Clubhouse and Splash in the Boro), and retail outlets.

\section{The Product}

The results suggested that the main benefit to the primary audience was opportunities for fun and interaction with their families and friends. Thus, opportunities for fun and interaction with families should emphasize "special" times with families and friends, which differed from the original VSS program, which emphasized only fun times with friends. Other benefits included fun and "getting to go out and play." The results also suggested products for the primary and secondary audiences. In this case, the product for the primary audience ( 8 - 13 year olds) is a behavior (i.e., physical activity), 60 minutes of moderate to vigorous physical activity most days of the week. The product for the secondary audience (adults) is 60 minutes of moderate to vigorous activity with their 8 - 13 year olds most days of the week.

\section{Scorecard}

Although used effectively in Iowa and Kentucky, the traditional, larger Scorecard representing 18-24 hours of activity did not test well with youth and parents in rural, southeast Georgia. Parents suggested two different options based on other programs in the local community. The first was a smaller Scorecard, the size of a library or 'punch card,' with five spaces each representing one hour of physical activity. This adaptation is similar to the original implementation of VSS in Lexington, Kentucky, where the Scorecard was originally based on a library rewards program in the local community. The front of the Scorecard contained messages to promote the program such as "Play,' 'Dance,' 'Jump,' and 'Fun.' This side of the Scorecard contained a link to a website that directed participants to free- or reduced-priced activities within the local community. The CAB suggested that parents be able to sign off on two of the five squares on the front of each Scorecard. The back of the Scorecard contained a list of locations where participants could turn in their Scorecards to receive prizes and a space for participants to write the last four digits of their phone number. This allowed program planners to track participation over time and activity at specific locations in the local community.

The second suggestion by parents regarded a new 'prize' for completed Scorecards. This centered on the use of a chain with fobs (i.e., 'dog tags'), representing participation the VSS program. A local school had recently used a fob in a rewards program, and parents recommended that the VSS program adopt a similar item. Youth would receive one fob for each completed Scorecard, and could use fobs as tokens to receive rewards. Rewards were scheduled in increments of $1,2,4$, and 6 fobs with corresponding prizes in the form of VSS bracelets, VSS t-shirts, VSS drawstring bags, and a sports equipment item (e.g., basketball, soccer ball, or jump rope). Participants were eligible for additional prizes. Completed cards were collected and compiled for a drawing at the grand finale. Participants could increase the likelihood of obtaining a major prize by completing multiple cards. Major prizes were selected with input from parents and the $\mathrm{CAB}$, with the requirement that each prize promote physical activity. These included bicycles and an X-box 360 with Kinect. 
Figure 1. Scorecard from Southeast Georgia

Front of Card

RUN

\section{VERB $^{\mathrm{TM}}$ Summer Scorecard

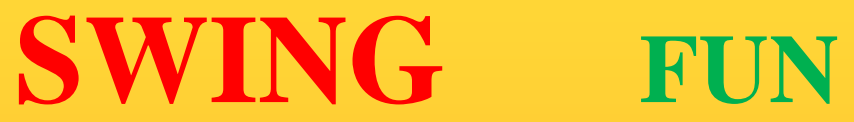

CLIMB

SWIM

CLIMB

DANCE

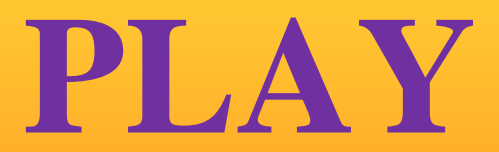

\section{JUMP}

Visit the site for cool deals and events in the community!!! www.verbsummerscorecardga.com

Note: 1 square $=60$ minutes of moderate to vigorous physical activity

Back of Card

\section{Parents are allowed to sign a maximum of $\underline{\text { TWO }}$ squares}

Once all squares have been filled, cards must be turned into any of the three locations listed below to receive VERB ${ }^{\mathrm{TM}}$ Summer Scorecard prize.

- The Clubhouse

- $\quad$ Boys and Girls Club

- $\quad$ Parks and Recreation Department

Name:

Youth or Adult

Address:

Last 4 digits of phone number: 


\section{Barriers and Facilitators}

Formative research results indicated that primary barriers to the primary audience included family work schedules, feeling afraid or unsafe, and a lack of free and reduced price physical activities in the rural community. Some youth also reported being afraid of interactions with certain peers, requiring that it be supervised. Parents and families comprised the secondary audience. According to focus group results, the benefits to offer families included opportunities for socialization in the community, happy families, and healthy relationships with their children. In addition, many parents were concerned with physical fitness of their children, in view of the attention given to the obesity crisis at school and in the media. The major barriers to participation in VSS mentioned during focus groups included: work schedules, competing activities on the weekend (i.e., errands), lack of transportation, and lack of funds for physical activity opportunities. In addition, many parents reported suffering from low motivation as a result of busy work weeks. Benefits discussed in relation to other sources of support included increased youth program toward physical fitness, increased community engagement, and, specific to businesses, increased consumption of goods and services. As discussed in focus groups, barriers to other sources of support for program implementation included multiple requests for assistance given the small size of the community, lack of staff to support additional physical activity opportunities, and limited resources.

\section{Promotion}

The research results suggested that the following messages should be used to promote VSS to the specific audiences. Primary Audience - "Go out and play"

Secondary Audience - "Take time out to have fun with your children”

Other Sources of Support - "Support for VERB Summer Scorecard will build your connection to the community" and/or "Support for VERB Summer Scorecard will help your students reach physical fitness goals.”

Core Messages - "Verb-It's What You Do," "VERB, Go Out and Play,” "VERB, A Fun Day with Family”

The results identified specific channels for disseminating information. The following channels, specific to each audience type, were used. For the primary audience, schools, Boys and Girls Club of Bulloch, Parks and Recreation Department, word of mouth, visual Scorecard, and local radio stations, including a Boys and Girls Club station. For the secondary audience, schools, Boys and Girls Club of Bulloch, Parks and Recreation Department, word of mouth, youth, and local radio stations, including a Boys and Girls Club station. Other outlets included face-to-face outreach, email, and participation in the CAB. Parents and youth also recommended campaign spokespersons. The results suggested, for the primary audience, other youth and families, and for secondary audiences, families and members of the community. Further, the primary promotional strategy would be word of mouth, facilitated by the chain and fob and the Scorecard.

\section{Placement}

VSS activities included the following: Kick Off University Recreation Activity Center (field), which included registration, signing of legal waivers, presentation of Fitness Grams for baseline data, parent's sign up for carpools, distribution of the summer calendar (flyer), distribution of chains and the first scorecard, participation in activity stations, and activities open to families and younger children. Snap Fitness, a 24-hour gym and fitness center with cardio, strength, and fitness plans in Statesboro, registered youth for free yoga, zumba, and aerobics classes. At registration, these classes were popular with youth; however, only small numbers (i.e., 4 or less) showed up for each class. To increase the incentive to attend, SNAP Fitness allowed parents a free hour of working out while their children were in class. Despite this incentive, attendance remained low. The Clubhouse, a physical activity outlet in Statesboro, offered a 'cool deal' in which youth with a Scorecard could bowl two free games,. At the end of the summer, a grand finale, including completion and submission of Scorecards and drawing for prizes for parents and youth, was held for participants and other children in the age group at the Boys and Girls Club. In the drawing, participants received prizes, including a Kinect, a gift card to a local sports store, and day passes to Splash in the Boro. Each child received a VERB t-shirt and a VERB drawstring bag containing coupons for free food in Statesboro. Further, before prizes were disseminated, children at the Grand Finale participated in an hour of structured physical activity.

\section{Summary of Program Implementation in Summer Years One through Three}

Initial planning, the first stage of the social marketing process, began in the fall of 2012. Preliminary discussions of the needs of the Boys and Girls Club and the history of VSS resulted in the formation of a partnership between the first author's college and the lead community partner, the Boys and Girls Club of Bulloch County. The decision was made to pursue financial support for the program through the Georgia Healthcare Foundation and to invite members of the community to an introduction to the need for physical activity programming in rural communities and the VSS program. The initial planning meeting was held in February 2012, was attended by twelve individuals representing university researchers, the Boys and Girls Club of Bulloch County, local public schools, the library, and communitybased organizations. At this meeting, two key decisions were made: 1) adaptation of the program was necessary based on the nature of rural Georgia and 2) the first summer should be limited to families served by the Boys and Girls Club. The latter decision was made based on the desire to start small and a need to meet the needs of underserved, African American youth in the community. For each year, the program coordinators were hired or volunteered from graduate students at our college. A total of 55 youth registered for the program in the summer of 2012, 58 registered in the summer of 2013, and 27 registered in 2014. Scorecard completions were very low across all three years, with only approximately $10-15 \%$ of youth actually tracking their physical activity and turning in their Scorecards for prizes. This occurred despite efforts to make Scorecard return and prize pick-up an easy process. Registration 
numbers were higher in years 1 and 2 because of our partnership with the Boys and Girls Club of Bulloch County. In the third year, this community partner decided to pursue different options, resulting in decreased numbers of participants and fewer opportunities for offering free and reduced cost activities. Attempts were made to recruit participants through the local school district via morning announcements and flyers and through flyers at the Recreation Department; however, these efforts were unsuccessful. After three years of program implementation, with low levels of community support and interest in the program despite multiple radio station ads, working with the school board, other outreach efforts, and the loss of our community partner, the program was ended in 2014.

\section{DISCUSSION}

The purpose of this paper was to provide a case study of program adaptation of an evidence-based intervention, VSS, in rural Georgia. Qualitative formative research results are presented, along with a summary of program implementation from the three years of its existence. Challenges are noted, and lessons learned from three years of implementation of VSS in rural Georgia are discussed.

According to Seifer and Maurana (2000), to create a successful partnership, academic and community partners should consider certain principles. Of the recommendations outlined, the implementation of VSS Bulloch County lacked three principles in developing its partnership with the local community partner. These are as follows:

First, the roles and process of the partnership should be established and agreed upon by all partners. The purpose of the $\mathrm{CAB}$ was to ensure that community stakeholders had a voice in program implementation. The first meeting introduced the community partners and stakeholders to the VSS program and there was a discussion of how each stakeholder could serve the project. During the first year of implementation, $\mathrm{CAB}$ meetings were held monthly and were well attended; the $\mathrm{CAB}$ was supportive of the project. However, its members were unwilling to commit to specific project responsibilities, such as planning activities, attendance at VSS functions, and hosting VSS events. Many of the project's processes, such as participant recruitment, acquiring financial support, and solicitation of participant incentives and prizes, fell on the academic partners to complete. Involvement of the CAB was essentially limited to attending the meetings. This low involvement continued in the second and third years. By the third year, the active $\mathrm{CAB}$ members included only the academic partners. In previous VSS programs, the CAB members have been more involved in the planning and implementing process (Bryant et al, 2007; Bryant et al, 2008). Community partnership is essential for VSS program implementation. Although enthusiasm for the program was present, the academic partners learned that enthusiasm did not consistently translate into action. As a conclusion, community capacity assessments should be completed to establish if the community is ready to commit to change and if the necessary resources are available to support the effort.
Second, a balance of power between partners should exist, and resources should be shared. When community organizations and Universities form partnerships, both parties can reap the benefits, but the benefits to be shared must be agreed early in the planning phase. Throughout the three-year implementation, the community partners contributed a location for CAB meetings (years 1 and 2) and allowed recruitment to take place with their tween population (years 1 and 2). The responsibility of recruitment was facilitated by the academic partners. In year 3, limited resources were shared by community partners. The academic partners learned that, before program planning begins, the balance of power must be pre-determined. Both parties should be aware of each other's expectations of responsibilities and duties. It is possible that, for this program, the expectations of the university partners were too great for the organizations. Typically, rural areas have sparse resources, including those of personnel and funding. To improve upon the resources shared, the academic and community partner should, prior to program implementation, develop a memorandum of understanding so that each entity understands the resources required and the party responsible for providing each resource. This memorandum should also include a statement specific to program recognition. It is recommended that both parties receive equal credit for program implementation.

Third, communication should be clear and open. Successful community partnerships exist when academic partners are willing to listen to community partners and stakeholders and keep each party engaged in all phases of planning and implementation. The academic partners in the Bulloch County VSS project followed the steps of CBPM and employed means of communication used in other VSS programs. Monthly CAB meetings were held (years 1 and 2); email communication and phone calls were utilized to update community stakeholders with planning decisions between meetings; and, during the first year, a CAB planning retreat was hosted prior to the kickoff to share results from the formative research collected during March and April 2012. At times, it was difficult to receive responses from community stakeholders outside the $\mathrm{CAB}$ meetings. The university partners learned that, for rural areas such as this, communication channels should be agreed upon by all stakeholders to ensure that standard procedures are followed to maintain clear communication among all involved. It might also be necessary to identify more creative means of communication such as the use of social media to involve local community partners. Creative communication channels might require technology training for both parties to make certain that all stakeholders can utilize the tools.

Three other issues limited the success of the VSS program as implemented in Bulloch County, GA. First, for all three years, there was a lack of a community level program champion. We relied on graduate students, who were completing their practicum requirements and were not necessarily invested in the success of the program. One graduate student coordinator, in particular, struggled to complete her assigned duties throughout the spring and fall semesters of the second program year (2013), which upset 
our community partner. Implementations of VSS in other communities have been successful, in large part, because they were led by an active community coalition and an enthusiastic, invested program champion (Bryant et al, 2007; Bryant et al, 2008).

The second limitation was that of evaluating the program. Because of difficulties with administering pre- and post-test evaluations at the Boys and Girls Club in years one and two and the low levels of Scorecard submissions across all program years, program evaluation was virtually impossible. Thus, this report has focused on providing a case study and lessons learned.

The third issue that prevented the success of VSS was the lack of action outlets and community partners to offer free and reduced-priced activities to youth. As discussed previously, at the core of VSS is the availability of action outlets, or places where youth can be physically active for free or at low cost. In rural communities such as this, there are limited action outlets. We partnered with major action outlets in our area but were turned down by local dance studios and gymnastics, which restricted our reach and ability to engage youth in physical activity. Thus, we were unable to provide them with a variety of outlets that are generally present in suburban and urban communities.

Limitations of this case study should be noted. First, the qualitative formative research was conducted with a small number of parents and youth, limiting the generalizability of results. Second, program evaluation is lacking, thus preventing an assessment of the success of the adapted VSS program. The strengths of this case study lie in its presentations of lessons learned in adapting evidence-based interventions in rural communities.

\section{CONCLUSIONS}

In regard to health promotion efforts, rural communities have barriers that contribute to negative health behaviors and resistance to change. The limited capacity of rural communities makes these barriers difficult to overcome, even during implementation of evidence-based practices. Additional efforts are needed to capture stakeholder buy-in and to build capacity at the community level, requiring a more profound engagement with the community.

The results of this case study are representative of a problem facing many rural communities in Georgia. Nevertheless, lack of capacity at the community level to address physical activity and obesogenic behaviors are not reasons to ignore the problem. Based on the lessons learned in this study, two recommendations are made for promoting physical activity in rural communities of Georgia. First, public health practitioners need to be aware of their role in the context on physical activity behavior. In addition to physical interaction of the population with the environment, sociocultural norms must be assessed. Although rural communities may have access to environmental resources, such as community parks and sports facilities, these may be underutilized and inaccessible to some members of the community. Overcoming norms that hinder physical activity requires an in-depth knowledge of the community, which can be gained through community mapping and interaction with members of the community. Second, when planning and implementing a community-based program, greater buy-in is needed from community stakeholders, and these stakeholders should take an active role in program communication and representation. Public health practitioners will need to provide additional training on the rationale for the program and the general method of implementation. Opportunities for physical activity exist in rural settings, but changing physical activity behavior without access to appropriate resources is difficult. Therefore, education may be needed before involving stakeholders and engaging the audience, so that both groups are able to provide suggestions that are feasible and meet recommended physical activity guidelines.

\section{Acknowledgements}

The authors wish to thank the Georgia Health Foundation for funding the first year of the program (2012). Additional funding was received through the Child Heath Coalition, the Jiann-Ping Hsu College of Public Health, faculty and staff donations made to our foundation account, and Wal-Mart.

\section{References}

Alfonso, M.L., McDermott, R. J., Thompson, Z., Bryant, C.A, Courtney, A. H., Jones, J. A., .....Zhu, Y. (2011). Vigorous physical activity among tweens VERB summer score card program, Lexington, Kentucky, 2004-2007. Preventing Chronic Disease, Public health Research, Practice and Policy, 8(5), $1-14$.

Alfonso, M.L., Nickelson, J., Hogeboom, D., Nichols, J., Bryant, C.A., McDermott, R.J., \& Baldwin, J.A. (2008). Assessing local capacity for intervention. Evaluation and Program Planning, 31, 145-159.

Alfonso, M.L., Thompson, Z., McDermott, R. J.,Colquitt, G., Jones, J. A., Bryant, C.A., \& Zhu, Y. (2013).VERB Summer score card: Increasing tween Girls' Vigorous physical activity. Journal of School Health, 83(3), 164-170.

Brown, T., \& Summerbell, C. (2009). Systematic review of schoolbased interventions that focus on changing dietary intake and physical activity levels to prevent childhood obesity: an update to the obesity guidance produced by the National Institute for Health and Clinical Excellence. Obesity Reviews, 10, 110-141.

Bryant, C.A., Courtney, A. H., McDermott, R. J., Alfonso, M.L., Baldwin, J. A., Nickelson, J., .....Zhu, Y. (2010). Promoting physical activity among youth through community based prevention marketing. Journal of School Health, 80(5), 214-224.

Centers for Disease Control and Prevention. (2015a) Physical Activity and Health. Retrieved from http://www.cdc.gov/physicalactivity/basics/pa-health/index.htm.

Centers for Disease Control and Prevention. (2015b). Nutrition, Physical Activity and Obesity: Data, Trends, and Maps. Retrieved

from http://www.cdc.gov/nccdphp/DNPAO/index.html.

Corbett, A., Gratale, D., Ellis, W., Revere, C., \& Chang, D. I. (2014). Childhood Obesity Prevention Strategies for Rural Communities. Retrieved from http://www.ashaweb.org/wpcontent/uploads/2014/08/Childhood-Obesity-PreventionStrategies-for-Rural-Communities.pdf

Janssen, I., \& LeBlanc, A. G. (2010). Systemic review of the health benefits of physical activity and fitness in schold aged children and youth. International Journal of Behavioral Nutrition and Physical Activity, 7(40), 1-16.

Martin, S.L., Kirkner, G. J., Mayo, K., Matthews, C. E., Durstine, J. L., \& Hebert, J. R. (2005). Urban, rural, and 
regional variations in physical activity. The Journal of Rural health, 21(3), 239-244.

Nemet, D., Barkan, S., Epstein, Y., Ffriedland, O., Kowen, G., \& Eliakim, A. (2005). Short and long term beneficial effects of a combined dietary-behavioral-physical activity intervention for the treatment of childhood obesity. Pediatrics, 115(4), e443e449.

Plowman, S.A. \& Meredith, M.D. (2013).

FitnessGram/ActivityGram reference guide. Dallas, TX: The Cooper Institute.

Seifer, S. D., \& Maurana, C. (2000). Developing and sustaining community-campus partnerships: Putting principles into practice. In K. Connors \& S. D. Seifer (Eds.), Partnership perspectives (pp. Vol. I, 7-11). San Francisco, CA: Community Campus Partnerships for Health.
Trickett, E.J., \& Beehler, S. (2013). The ecology of multilevel interventions to reduce social inequalities in health. American Behavioral Scientist, 57, 1227-1246.

US Department of Health and Human Services. (2010). Healthy People 2020. Retrieved from

https://www.healthypeople.gov/sites/default/files/HP2020_broch ure_with_LHI_508_FNL.pdf

US Department of Health and Human Services. (2011). The Health And Well-Being Of Children In Rural Areas: A Portrait Of The Nation 2007. Retrieved

from http://mchb.hrsa.gov/nsch/07rural/moreinfo/pdf/nsch07rur al.pdf.

Warburton, D. E.R., Nicol, C. W., \& Bredin, S. D. (2006). Health benefits of physical activity: the evidence. Canadian Medical Association Journal, 174(6), 801-809. 